\title{
Fallopian Tube Recanalization (F.T.R): application of Interventional Radiology (I.R) post hysterosalpingography in management of female infertility at rural hospital
}

\author{
Abhinav Amarnath Mohan*, Gaurav O. Sharma, Pankaj J. Banode
}

DMIMS Jawaharlal Nehru Medical College, Department TIFAC CORE Interventional Radiology, Acharya Vinoba Bhave Rural Hospital (A.V. B. R. H) Sawangi Meghe, Wardha, Maharashtra, India

Received: 28 June 2018

Accepted: 06 July 2018

\section{*Correspondence:}

Dr. Abhinav Amarnath Mohan,

E-mail: dnbabhinavmohan@gmail.com

Copyright: (c) the author(s), publisher and licensee Medip Academy. This is an open-access article distributed under the terms of the Creative Commons Attribution Non-Commercial License, which permits unrestricted non-commercial use, distribution, and reproduction in any medium, provided the original work is properly cited.

\section{ABSTRACT}

Background: Infertility is defined as inability to conceive even after 1 year of unprotected intercourse. Tubal blockage is one of the common causes of primary as well as secondary infertility in females. Fallopian tube recanalization (FTR) an interventional radiological procedure is one of the most promising, effective, minimally invasive and cost-effective technique in patients having infertility owing to tubal blockage. The aim is to study the cause, hysterosalpingography findings, and outcome of fallopian tube recanalization by interventional radiological procedure in patients with tubal-blockage presenting with infertility.

Methods: This was a prospective observational study of women with primary or secondary infertility presenting to interventional radiology department. The patients either had already undergone hysterosalpingography (HSG) or came for HSG. Fallopian tube recanalization was done as per institutional protocol. Hysterosalpingography abnormalities, outcome and complications of fallopian tube recanalization procedure were studied.

Results: In this study of 87 patients unilateral or bilateral tubal blockages were seen in 16 and 24 patients respectively. Majority of the patients had Segment I proximal block. Bilateral recanalization could be successfully done in 12 patients (24 tubes) with bilateral Proximal Tubal Blockage (PTO). Unilateral recanalization was possible in 12 patients (tubes) with unilateral proximal block and 8 tubes with bilateral proximal tubal block. 10 tubes with PTO could not be recanalized. 5 cases diagnosed with bilateral Distal Tubal Block (DTO), recanalization was not attempted and were referred for appropriate gynecological management. Minor complications were noted in 8 patients while no major procedure related complications were observed.

Conclusions: Fallopian tube recanalization (by interventional radiology procedure) in patients with fallopian tube blockage diagnosed on HSG is found to be cost effective, minimally invasive and have low complication rate. It is associated with excellent outcome in terms of technical success and improved conception rate.

Keywords: Fallopian tube recanalization, Hysterosalpingography, Infertility, Interventional Radiology, Tubal blockage

\section{INTRODUCTION}

With advances in assisted reproductive techniques and developments in minimally invasive surgical techniques, the management of female infertility has evolved exponentially with better outcomes in recent times. The availability of state of art infertility centers catering and providing umbrella care for both husband and wife has made it possible to provide comprehensive treatment options for both males and females. However, the cost 
involved and availability of these state of art facilities and their location in major cities has been a major constraint in using these services by rural population.

Female infertility is multi-causal and multi-factorial ranging from hormonal factors to uterine receptivity with other significant factors like pathologies of ovarian folliculogenesis and differentiation. ${ }^{1}$ Apart from this, sometimes the very 'crucial factor' for conception/ fertilization to occur is "patency of pathway" for travel and union of sperms and ovum with implantation into uterus. Thus, these anatomical structures merit basic consideration and patency of these passages and its imaging with simple Hysterosalpingography. HSG is procedure of choice before any advanced assisted reproductive techniques are carried out. The availability of Hysterosalpingography and its reproducibility with relatively economical and minimally invasive nature merits consideration. ${ }^{2}$ It can reliably diagnose abnormalities of size and shape of uterus. Moreover, it can reliably detect presence of fallopian tube blockage. Selective salpingography and Fallopian Tube Recanalization (FTR) is minimally invasive and procedure of choice in diagnosis and management of tubal blocks with primary/baseline HSG showing either partial or complete tubal blocks. ${ }^{3}$

Proximal tubal blockage present with narrowing or blockage segments I, II and III of fallopian tubes which is lined by few ciliated and more of secretary epithelial cells which can either be isolated presenting unilaterally or bilaterally or in association with distal tubal blocks. ${ }^{4}$ Causes of proximal tubal block are inclusive of but not limited to endometriosis, myomas, polyps and Salpingitis Isthimica Nodosa (SIN). True tubal blockages need to be differentiated from conditions such as amorphous material or dried mucus secretions and corneal or tubal spasm. Proximal tubal blocks are mostly amiable to selective salpingography and FTR. Transcervical fallopian tube catheterization is being increasing employed in management of these cases. ${ }^{5}$

Distal tubal block / obstruction (DTO) cause distension wide lumen of fallopian tubes up to $1 \mathrm{~cm}$ to $1.5 \mathrm{~cm}$ prior to the level of distal tubal block involving infundibular part of fallopian tube (segment IV). This part of fallopian tube is lined with more of ciliated epithelial cells and few secretary cells. ${ }^{6}$ The common causes of DTO include genito-urinary infections or Pelvic Inflammatory Disease (PID), peri-tubal adhesions or extensions of inflammation or infections involving from adjacent structures, systemic infections (like tuberculosis) etc. ${ }^{7}$ Distal tubal blockage needs to be differentiated from tubal diverticulum on HSG. $^{8}$

Unrecognized tubal obstructions/ blocks (Partial or complete) can lead to repeated failure in various Assisted Reproductive Techniques (ARTs) because they prevent sperms from reaching into ampullary part of fallopian tube for fertilization with ovum/ female oocyte. ${ }^{9}$ As per
NICE guidelines and recommendations of American society for reproductive medicine (ASRM) and WHO, FTR by interventional radiological method has primary role in management of PTO, both for diagnostic assessment value and therapeutic applications with additional merits being less expensive and minimally invasive as compared to other non-radiologic methods. ${ }^{10}$

\section{METHODS}

This was a prospective observational study which was done in interventional radiology suite on outpatient department (O.P.D) basis in a rural medical college. 87 patients having infertility after informed consent were included in this study on the basis of a predefined inclusion and exclusion criteria. These patients have either already undergone HSG outside and referred for FTR or came for preliminary HSG and FTR if required. Selective salpingography and FTR was done on the basis of predefined protocol.

\section{Inclusion criteria}

- Female patients with infertility (primary or secondary) who came on 8th, 9th or 10th day of menstrual cycle.

- $\quad$ Patients giving informed consent.

\section{Exclusion criteria}

- Pregnant patients

- Urine pregnancy test positive.

- Contraindication to pregnancy (mitral stenosis, cyanotic congenital heart diseases etc.).

- Active uterine bleeding or recent curettage.

- Severe intrauterine adhesions or Ashermans syndrome.

- Acute Pelvic Inflammatory Disease (PID).

- Recent ART's, history of recent tubal operations.

- Patients in whom HSG was contraindicated like allergy to contrast agent.

FTR technique: Before the procedure comprehensive counseling of all the patients was done regarding the procedure and its possible outcome. HBsAg and HIV ELISA was done in all cases. Informed consent for the procedure was taken. Patient was kept in lithotomy position and routine HSG was performed under all aseptic precautions. Salpingography was done using selfretaining balloon catheter $(5 \mathrm{~F})$ with coaxial $(3 \mathrm{~F})$ selective salpingography catheter. Non-ionic radiologic contrast media and sterile normal saline was used for the procedure. With selective salpingography if obstruction was overcome with free passage of contrast into peritoneal cavity it was considered that the salpingography is technically successful. However, in cases where there was no free spillage of contrast into the peritoneal cavity a 0.018 -inch highly flexible guidewire was passed through the obstruction (in selected cases) 
into the ampullary segment, followed by check flush injection. A free flow of contrast with visualization of distal fallopian tubal anatomy and free spillage into peritoneal cavity was taken as successful FTR. After the procedure patients were kept for observation for 3 hours and were prescribed analgesics and antibiotics.

Microsoft office was used for preparing manuscript as well as preparation of charts and graphs. Statistical analysis was done by calculating means for the continuous data using SSPS 16 software.

\section{RESULTS}

Our study consisted of 87 female patients of reproductive age group and having history of primary or secondary infertility who have either already undergone HSG outside or came for preliminary HSG. Out of these 87 women majority of the patients belonged to age group of $25-29$ years $(40.22 \%)$ followed by $30-34$ years $(24.43 \%)$ and 20-24 years (18.39\%). In present study youngest and oldest patient was 19 years and 43 years of age respectively.

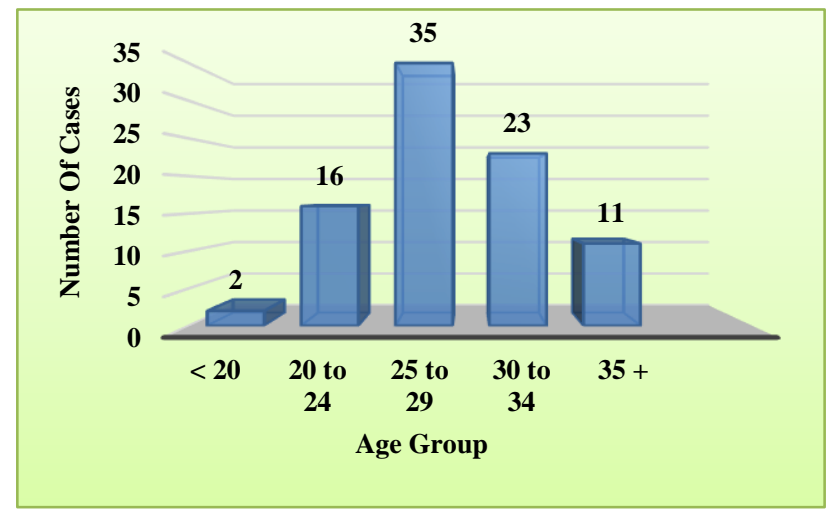

Figure 1: Age group of the studied cases.

Out of 87 studied cases 64 patients $(73.56 \%)$ had primary infertility while 23 patients $(26.43 \%)$ had secondary infertility.

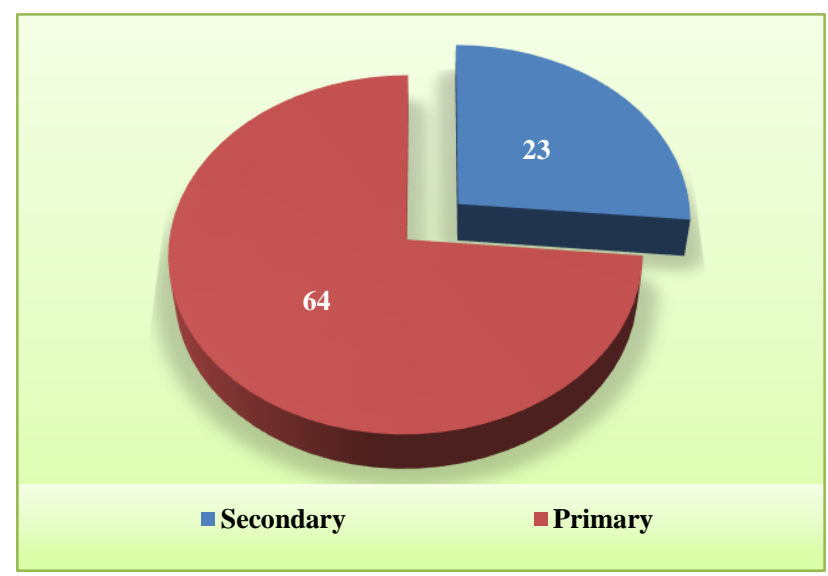

Figure 2: Type of infertility (primary versus secondary).

The study of cases on the basis of presence of present or past risk factors for infertility showed that menstrual abnormalities were seen in 53 patients. The most common menstrual abnormality was found to be oligomenorrhoea $(32.18 \%)$ followed by dysmenorrhea $(21.83 \%)$ and menorrhagia $(6.89 \%)$. Menstrual cycles were normal in 34 patients $(39.08 \%)$.

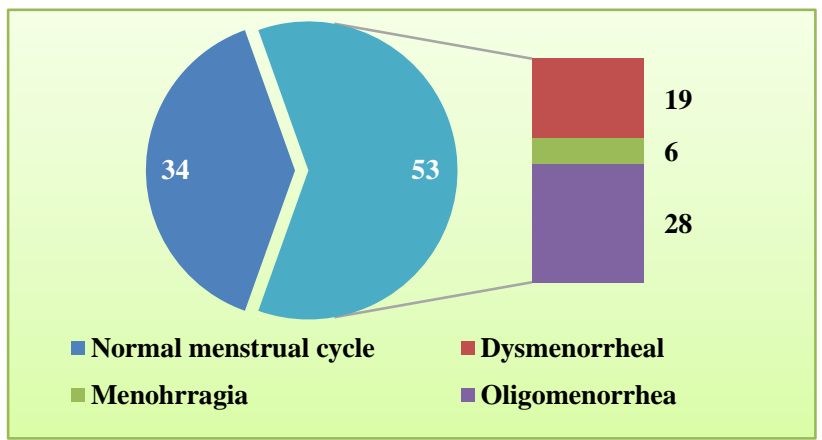

Figure 3: Menstrual history of the studied cases.

On the basis of history 52 patients have some or the other factors pointing towards the cause of infertility. 20 patients had the history of $\mathrm{P} / \mathrm{V}$ discharge or genitourinary infection $(22.98 \%)$, while 10 patients $(11.49 \%)$ had the history of pelvic inflammatory diseases. Cervical stenosis, history of tuberculosis, H/o tubal surgery or ligation, H/o operated ectopic gestation were other relevant factors.

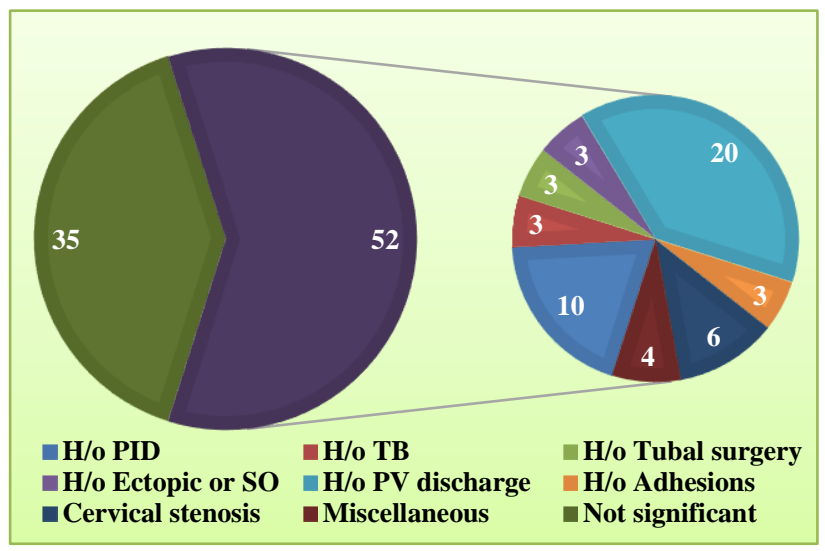

Figure 4: History of conditions affecting genitourinary tract.

Hysterosalpingography showed that majority of the patients had normal size, shape and surface of uterus. Small sized uterus was found in 6 cases $(6.89 \%)$ while Mullerian anomalies (like arcuate, unicornate and bicornuate uterus) were seen in 6 patients $(6.89 \%)$. Irregular surface with filling defects were seen in 3 patients $(3.44 \%)$. 
Other findings like cervical stenosis, tubal spasm (relieved by anti-spasmodic), hydrosalpinx and loculated spillage was seen in $6(6.89 \%), 7(8.04 \%), 5(5.74 \%)$ and $5(5.74 \%)$ patients respectively.

Table 1: HSG findings in the studied cases.

\begin{tabular}{|lllll}
\hline HSG uterine findings & \multicolumn{3}{c}{ Number of cases } \\
\hline Size & Normal $=81$ & Small $=6$ & Large $=0$ & Bicornuate $=1$ \\
\hline Shape & Normal $=81$ & Arcuate $=2$ & Unicornuate $=3$ & \\
\hline Surface & Smooth $=84$ & Irregular with filling defects $=3$ & \\
\hline Other & Cervical stenosis $=6$ & Tubal spasm $=7$ & Hydrosalpinx $=5$ & Loculated spillage $=5$ \\
\hline
\end{tabular}

Table 2: Salpingography findings in the studied cases.

\begin{tabular}{|ll|}
\hline Salpingography findings & No. of cases \\
\hline Unilateral tubal blockage & 16 \\
\hline $\begin{array}{l}\text { Bilateral tubal obstructions } \\
\begin{array}{l}\text { Patent tubes with free spillage } \\
\text { of contrast into peritoneal cavity } \\
\text { (normal tubes) }\end{array}\end{array}$ & 24 \\
\hline
\end{tabular}

Salpingography in the studied cases showed that in majority of the patients both fallopian tubes were normal with free spillage of contrast into the peritoneal cavity
(54.02\%). Unilateral and bilateral tubal blockage was seen in 16 and 24 patients respectively.

Out of the patients in whom tubal blockade was diagnosed on the basis of salpingography there were 16 patients with unilateral tubal blockage and 24 patients with bilateral tubal blockage making the number of affected tubes to be 64 . Out of these affected tubes majority of the tubes were blocked in cornual segment (segment I) followed by infundibular block. Isthmic and ampullary tubal segments were found to be less frequently involved.

Table 3: Tubal blockage in studied cases.

\begin{tabular}{|c|c|c|c|}
\hline Types of tubal block & Proximal tubal block & Distal tubal block & Total number of blocked tubes \\
\hline \multirow{3}{*}{ Segment involved } & Segment I (Cornual) $=46$ & \multirow{3}{*}{$\begin{array}{l}\text { Segment IV } \\
\text { (infundibular) }=10\end{array}$} & \multirow[t]{3}{*}{ 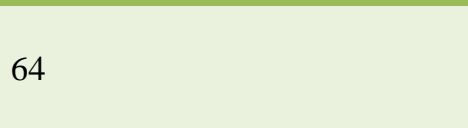 } \\
\hline & Segment II (isthmic) $=05$ & & \\
\hline & Segment III (ampullary) $=03$ & & \\
\hline
\end{tabular}

Table 4: Type of tubal obstruction.

\begin{tabular}{|ll|}
\hline Type of tubal obstruction/ block & No. of tubes $n=64$ \\
\hline Proximal tubal obstruction (PTO) & 54 tubes \\
\hline Distal tubal obstruction (DTO) & 10 tubes \\
\hline
\end{tabular}

Out of 64 blocked tubes proximal tubal obstruction was noted in 54 tubes while distal tubal obstruction was seen in 10 tubes.
Total 54 proximal tubal blockages were noted in studied cases. Out of these 54 blockages bilateral recanalization was successful in 24 tubes. While unilateral recanalization was successful in 20 tubes. However, recanalization was not successful in 4 cases with unilateral proximal tubal block and 3 patients with bilateral proximal tubal block (6 tubes).

Table 5: Result of fallopian tube recanalization procedure in proximal blockage.

\begin{tabular}{|llll|}
\hline Result post FTR & Total proximal tubal obstructions $=54$ tubes & Cases with unilateral \\
Number of tubes & proximal tubal block & $\begin{array}{l}\text { Cases with bilateral } \\
\text { proximal tubal block }\end{array}$ \\
\hline Not recanalized & 10 tubes & 4 tubes (4 patients) & 6 tubes (3 patients) \\
\hline Unilateral recanalized successfully & 20 tubes & 12 tubes & 8 tubes \\
\hline Bilateral recanalized successfully & 24 tubes & Not applicable & 24 tubes \\
\hline
\end{tabular}


All the 5 patients diagnosed with distal tubal blockage had bilateral blockages (10 tubes). Recanalization was not attempted and referred back for appropriate management.

Table 6: Result of fallopian tube recanalization procedure in distal blockage.

\begin{tabular}{|l|l|l|}
\hline Result post FTR & $\begin{array}{l}\text { Cases with } \\
\text { unilateral } \\
\text { distal tubal } \\
\text { block }\end{array}$ & $\begin{array}{l}\text { Cases with } \\
\text { bilateral } \\
\text { distal tubal } \\
\text { block }\end{array}$ \\
\hline $\begin{array}{l}\text { Recanalization not } \\
\text { attempted }\end{array}$ & 0 & 5 (patients) \\
\hline $\begin{array}{l}\text { Recanalized } \\
\text { successfully }\end{array}$ & 0 & 0 \\
\hline Total & 0 & 10 (tubes) \\
\hline
\end{tabular}

The analysis of complications in studied cases showed that there were 8 patients with minor complications. The complications included vascular contrast opacification, asymptomatic fallopian tube perforation and uterine mucosal injury. No major complications were seen in any of the patients undergoing fallopian tube recanalization during the study period.

Table 7: Complications in the studied cases.

\begin{tabular}{|ll|}
\hline $\begin{array}{l}\text { Post procedure complication in } \\
\text { present study }\end{array}$ & $\begin{array}{l}\text { Number of } \\
\text { cases }\end{array}$ \\
\hline $\begin{array}{l}\text { Major complication/ death/ post } \\
\text { procedure hospitalization }\end{array}$ & Nil \\
$\begin{array}{l}\text { Vascular contrast opacification/ } \\
\text { intravasation }\end{array}$ & 4 \\
$\begin{array}{l}\text { Fallopian tubal perforation "without" } \\
\text { overt clinical manifestation or } \\
\text { requiring hospitalization }\end{array}$ & 3 \\
$\begin{array}{l}\text { Post procedure infection/ contrast } \\
\text { allergy/ reactions }\end{array}$ & 0 \\
\hline $\begin{array}{l}\text { Self-limiting uterine perforation/ } \\
\text { mucosal injury }\end{array}$ & 1 \\
\hline
\end{tabular}

\section{DISCUSSION}

Fallopian tube recanalization is increasingly being used for the management of primary and secondary infertility. Recanalization is possible, albeit with limited success, in cases of tubal blockage secondary to tubal fibrosis and in cases undergoing reversal of tubal ligations. Ramalingappa et al in their study of tubal recanalization after tubectomy for sterilization purpose found that laparoscopically sterilized patients had better chances of conception $(50 \%)$ following reversal than those who were sterilized by Pomeroy's method (30\%). The authors reported a pregnancy rate of $50 \%$ in cases where postreversal tubal length was more than $4 \mathrm{~cm} .{ }^{11}$ In patients with blocks secondary to SIN successes rates up to 80$85 \%$ have been achieved (employing micro glide-wire gentle manipulations in selective cases). Houston JG et al conducted a study to evaluate the technical success and outcome of fallopian tube recanalization (FTR) in salpingitis isthmica nodosa (SIN). SIN was observed in 22 of $349(6 \%)$ patients. FTR was attempted in 34 tubes in these 22 patients. Technical success was achieved in 23 of $34(68 \%)$ tubes affected by SIN. In 5 of the 11 failed recanalization, failure was due to distal obstruction. At least one tube was patent on selective postprocedural salpingography in 17 of $22(77 \%)$ patients. There were no recorded perforations or complications. At follow-up (mean 14 months), total, intrauterine, and ectopic pregnancy rates were $23 \%, 18 \%$, and $4.5 \%$, respectively. The authors concluded that FTR in SIN is associated with good results and, compared with previously reported results in unselected infertility patients, is associated with only a slightly less favorable intrauterine pregnancy rate and a comparable ectopic pregnancy rate. ${ }^{12}$

Proximal tubal obstruction caused by muscular, tubal or cornual spasms, viscid secretions, mucosal aggregates, amorphous debri or stomal edema can be managed by FTR with a good success rate. The FTR may not bear satisfactory results in cases with tubal obstruction secondary to endometriosis, chronic tubal edema or inflammation (Salpingitis) and cornual polyps. Chao $\mathrm{He}$ et al in a large study of tubal recanalization in proximal as well as distal tubal obstruction (using ozone treatment) found that proximal tubal recanalization of the treatment and the control group had no significant post-operative difference $(\mathrm{P}>0.05)$. However, contrary to the proximal recanalization rate, post-operative distal recanalization rate of the treatment group was significantly higher than that in the control group. The overall recanalization rate was significantly higher in the treatment group (93\%) as compared to the control group (79\%) 6-months after intervention $(\mathrm{P}<0.01)$. The results of this study were found to be highly encouraging for treating distal tubal obstruction in infertile females ${ }^{13}$. Applications of FTR were highlighted in studies conducted by Allahbadia GN et al and Thurmond AS et al. ${ }^{14,15}$ Hayashi $\mathrm{M}$ et al found that there is a definite increase in conception rate in Infertile patients with a unilateral proximally occluded tube and a contralateral patent tube following FTR. ${ }^{16}$

Proximal Tubal obstruction secondary to extensive luminal fibrosis, congenital segmental atresia, tuberculosis, leiomyomas, tuberculosis sequelae, failed surgical tubal anastomosis usually have poor outcome after FTR. One of the important aspect while doing FTR is age of the patient. ${ }^{17}$ It has been reported by various authors that the advance age at the time of FTR is associated with poor outcome in patients of infertility secondary to tubal blockage. With proper techniques the average success rate post FTR alone rises up to approximately $30-35 \%$ and when utilized in combination to ARTs, significant surge in successful achieved conception or fertility are observed in state of art centers. $^{18,19}$

The complications following FTR are usually minor and major complications are very rare. The complications 
which may be seen in the patients undergoing FTR may include vascular contrast opacification due to forceful contrast injection or tight fibrotic blocks, fallopian tube perforation with no clinical manifestation, uterine or cervical mucosal erosion or injury and rarely uterine perforation. Cornual/isthmic segment perforation may be seen owing to over enthusiastic hardware or guidewire manipulations instead of gentle and delicate interventional technique or less experienced operator. All these complications can be avoided with proper technique and in event of its occurrence can be managed conservatively. High technical success rate and low complications rate make this procedure desirable in comparison with more complicated and resourceintensive procedures. ${ }^{20}$

\section{CONCLUSION}

Fallopian Tubal recanalization in tubal Obstruction has been recommended in management of female infertility according to NICE guidelines, WHO and American society for reproductive medicine as preliminary diagnostic and therapeutic procedure of choice. Interventional radiological FTR is found to be cost effective and minimally invasive with excellent outcomes.

\section{Funding: No funding sources Conflict of interest: None declared Ethical approval: Not required}

\section{REFERENCES}

1. Chen LM, Wang RS, Lee YF, Liu NC, Chang YJ, Wu $\mathrm{CC}$, et al. Subfertility with defective folliculogenesis in female mice lacking testicular orphan nuclear receptor 4. Mol Endocrinol. 2008 Apr;22(4):858-67.

2. Schankath AC, Fasching N, Urech-Ruh C, Hohl MK, Kubik-Huch RA. Hysterosalpingography in the workup of female infertility: indications, technique and diagnostic findings. Insights Imaging. 2012;3(5):47583.

3. Thurmond AS, Rösch J, Patton PE, Burry KA, Novy M. Fluoroscopic transcervical fallopian tube catheterization for diagnosis and treatment of female infertility caused by tubal obstruction. Radiographics. 1988;8(4):621-40.

4. Honoré GM, Holden AE, Schenken RS. Pathophysiology and management of proximal tubal blockage. Fertil Steril. 1999 May;71(5):785-95.

5. Hall LD, Brodie MF. Fallopian Tube Interventions In: Mauro MA, Murphy KPJ, Thomson KR, Venbrux AC, Robert A, eds. Morgan Image-Guided Interventions EBook: Expert Radiology Series. $2^{\text {nd }}$ ed. Elsevier Saunders; 2014:1117.

6. Hunt JL, Lynn AA. Histologic features of surgically removed fallopian tubes. Arch Pathol Lab Med. 2002 Aug;126(8):951-5.

7. Kitchin JD 3rd, Nunley WC Jr, Bateman BG. Surgical management of distal tubal occlusion. Am J Obstet Gynecol. 1986 Sep;155(3):524-31.
8. Muzii L, Marana R, Mancuso S. Distal fallopian tube occlusion: false diagnosis with hysterosalpingography in cases of tubal diverticula. Radiol. 1996 May;199(2):469-71.

9. Al Subhi T, Al Jashnmi RN, Al Khaduri M, Gowri V. Prevalence of Tubal Obstruction in the Hysterosalpingogram of Women with Primary and Secondary Infertility. J Reprod Infertil. 2013;14(4):2146.

10. Practice Committee of American Society for Reproductive Medicine. Diagnostic evaluation of the infertile female: a committee opinion. Fertil Steril. 2012 Aug;98(2):302-7.

11. Ramalingappa A, Yashoda. A study on tubal recanalization. J Obstet Gynaecol India. 2012;62(2):179-83.

12. Houston JG, Machan LS. Salpingitis isthmica nodosa: technical success and outcome of fluoroscopic transcervical fallopian tube recanalization. Cardiovasc Intervent Radiol. 1998 Jan-Feb;21(1):31-5.

13. He C, Ma X. Distal fallopian tube recanalization using ozone treatment: a clinical study in two hundred tubal obstruction Chinese patients. Int J Clinical Exp Med. 2015;8(2):2958-61

14. Allahbadia GN, Merchant R. Fallopian tube recanalization: lessons learnt and future challenges. Women's Health (Lond). 2010 Jul;6(4):531-48.

15. Thurmond AS, Machan LS, Maubon AJ, Rouanet JP, Hovsepian DM, Moore A, et al. A review of selective salpingography and fallopian tube catheterization. Radiographics. 2000 Nov-Dec;20(6):1759-68.

16. Hayashi M, Hoshimoto K, Ohkura T. Successful conception following Fallopian tube recanalization in infertile patients with a unilateral proximally occluded tube and a contralateral patent tube. Hum Reprod. 2003 Jan;18(1):96-9.

17. Knuttinen MG, Jajko R, Scoccia B. Fluoroscopic Tubal Recanalization in Tubal Factor Related Infertility. Seminars Intervent Radiol 2014;31(3):269-71.

18. Al-Omari MH, Obeidat N, Elheis M, Khasawneh RA, Gharaibeh MM. Factors affecting pregnancy rate following fallopian tube recanalization in women with proximal fallopian tube obstruction. J Clinical Med. 2018;7(5):110.

19. Lang EK, Dunaway HH. Recanalization of obstructed fallopian tube by selective salpingography and transvaginal bougie dilatation: outcome and cost analysis. Fertil Steril. 1996 Aug;66(2):210-5.

20. Anil G, Tay KH, Loh SF, Yong TT, Ong CL, Tan BS. Fluoroscopy-guided transcervical, selective salpingography and fallopian tube recanalisation. J Obstet Gynaecol. 2011 Nov;31(8):746-50.

Cite this article as: Mohan AA, Sharma GO,

Banode PJ. Fallopian Tube Recanalization (F.T.R): application of Interventional Radiology (I.R) post hysterosalpingography in management of female infertility at rural hospital. Int J Reprod Contracept Obstet Gynecol 2018;7:3074-9. 